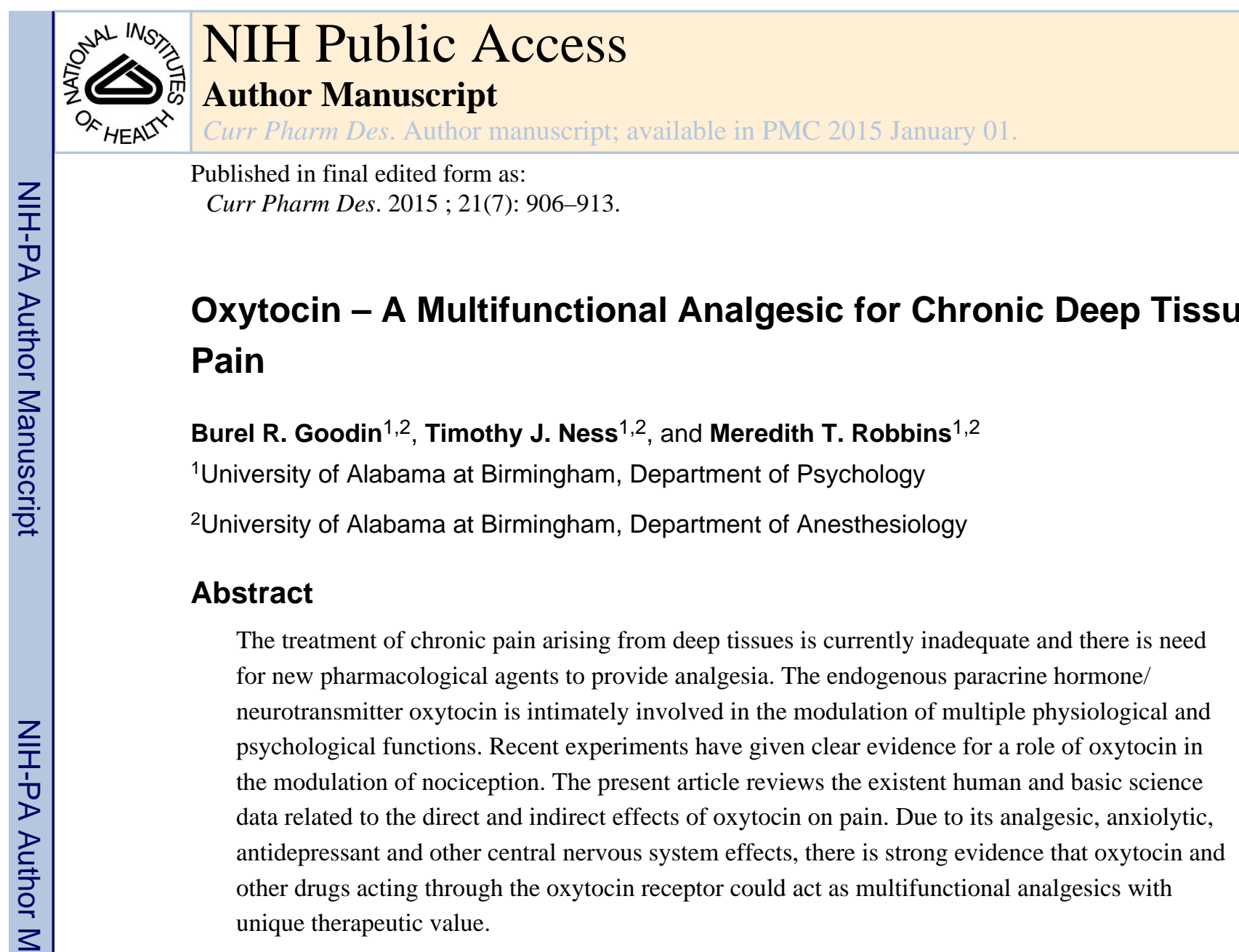

\title{
Keywords
}

oxytocin; visceral pain; musculoskeletal pain; nociception; analgesics; anxiolytics

\section{The Problem}

Pain is a ubiquitous experience among humans as well as many animal species and is commonly understood to be a normal sensation triggered in the nervous system as an alert to the possibility of injury and the need for rest and recuperation. In this instance, the experience of acute pain is adaptive and can be considered an expected consequence of illness, injury, and surgery, which most often resolves with healing. We have reasonably effective drugs for this type of pain with opioids and anti-inflammatories forming the mainstays of therapy. However, the experience of chronic pain is an entirely different matter. There is apparent pathological activation of the central nervous system (CNS), such that pain signals keep firing in the nervous system for weeks, months, even years beyond the expected period of healing or resolution of the source of pain. Often it is the case that the experience of chronic pain is not reliably associated with underlying pathology or disease severity. Therefore, chronic pain does not appear to serve an instrumental role in protecting the sufferer or in otherwise promoting adaptation and adjustment. For those afflicted and their caregivers, chronic pain all too commonly exerts deleterious effects on sense of well-

Conflicts of interest: The authors of this manuscript have no conflicts of interest related to its content. 
being and quality of life. Further, issues with anxiety and depression often become more prominent when they co-occur with chronic pain. Even more unfortunate is the fact that there are currently a limited number of drugs with demonstrated long-term effectiveness for controlling chronic pain. Those drugs that do have proven efficacy for providing pain relief also frequently produce significant side effects thereby limiting use.

If chronic pain was an uncommon malady, the limited number of effective drugs currently available for long-term management perhaps would be of minimal consequence.

Unfortunately, this is not the case as millions of Americans and people world-wide experience chronic pain [1]. A review of several epidemiological studies of chronic pain among adults revealed that prevalence estimates in the general population ranged from $2 \%$ to $40 \%$, with a median of $15 \%$ [2-4]. In addition to its human cost, chronic pain is an economic burden because it requires medical treatment, complicates medical treatment for other conditions, and hinders people's ability to work and function in society. Using the 2008 Medical Expenditure Panel Survey, Gaskin and colleagues recently showed that the total annual costs of chronic pain in the United States ranged from $\$ 560$ to $\$ 635$ billion in 2010 [5]. The value of lost productivity due to chronic pain ranged from \$299 to \$335 billion. Further, it was revealed that the annual cost of chronic pain was greater than the annual costs of heart disease ( $\$ 309$ billion), cancer ( $\$ 243$ billion), and diabetes ( $\$ 188$ billion). Taken together, these data attest to the unfortunate reality that many Americans may suffer from chronic pain at some point in their lives, and the resultant economic burden of chronic pain and its treatment is of significant magnitude. Chronic pain continues to represent a formidable current and ongoing public health crisis. As it relates to the focus of this review, the most common chronic pain conditions are those associated with deep tissue structures such as muscle (e.g. fibromylagia), the gut (e.g. irritable bowel syndrome, IBS), the bladder (e.g. interstitial cystitis/bladder pain syndrome, IC/BPS), other digestive organs (e.g. chronic pancreatitis), reproductive organs (e.g. dysmenorrhea, endometriosis, chronic prostatitis), and deep craniofacial structures (e.g. migraine and other types of headache).

For decades, the field of pain medicine has relied upon the use of opioids for both acute and chronic pain management [6]. However, adverse effects related to the long-term use of opioids for chronic pain can be severe and often lead to inadequate pain relief and ultimately forced drug discontinuation $[7,8]$. Some of the more effective and commonly used nonopioid medications for chronic pain are drugs that were initially developed to help control depression and anxiety. Antidepressants including the tricyclic class of agents, selective serotonin reuptake inhibitors (SSRIs) and serotonin/norepinephrine reuptake inhibitors (SNRIs) have become commonly used drugs in the treatment of many chronic pain conditions [9-11]. Other drugs identified serendipitously are the anticonvulsant agents such as carbamazepine, gabapentin and pregabalin [12]. Although there are currently multiple different pharmacological agents available in the United States for the treatment of chronic pain, effective and sustained pain relief as well as functional restoration comparable to premorbid levels unfortunately is rarely achieved. New, safe, and effective treatments for chronic pain, therefore, need to be developed. 


\section{Oxytocin as a Potential Solution}

With increased understanding of the neurobiology and pathophysiology of pain, new drug targets have been emerging, which may lead to novel therapeutic strategies. Currently, a number of potential targets including TRPV1, TRPA1, voltage-gated sodium channels, calcium channels, glutamate receptors, and cannabinoids, are being studied to determine whether they hold promise for future treatments, particularly for neuropathic and chronic pain conditions [13-17]. One potentially interesting mechanism of action is that associated with the endogenous nonapeptide, oxytocin (OXY), which has recently been recognized as an important mediator of endogenous analgesia [18-22]. OXY is uniquely multifunctional as it acts as both a neurotransmitter and as a paracrine hormone to regulate multiple physiological and CNS functions. Produced predominantly in the supraoptic and paraventricular nuclei (SON \& PVN respectively) of the hypothalamus, and following secretion into the blood, OXY is best known for its roles in parturition and lactation. However, it is intimately involved in normative social and psychological functions including maternal behaviors, attachment and affiliation associated with pair bonding, depressive mood, anxiety, memory, appetite, sexual function and stress regulation [e.g., 23-34]. Clinically, OXY has been used in the treatment of autism [35], sexual dysfunction [36], migraine [37], schizophrenia [38], drug addiction [39] and other CNS dysfunctions [40]. Extensive clinical use in experimental studies has identified few toxicities of OXY treatment [41] apart from those associated with accidental overdose [42,43] or use with co-morbidities such as gastroparesis [44]. OXY has known CNS actions on deep tissue functions via spinal actions such as alterations of uterine motility [45] and bladder emptying [46].

Peripheral and central actions of oxytocin, although related, appear to be functionally independent in primates [47]. Oxytocinergic neurons of the PVN have axonal projections to the spinal cord which form synaptic connections with neurons in the dorsal horn, and recent studies have implicated a role for the hormone as a spinal level neurotransmitter with a particular role in the modulation of first and second order sensory processing [48]. As this review will demonstrate, there is a growing line of evidence linking OXY to nociception and pain in animal and human models. A notable characteristic of OXY is that it is multifunctional in ways that are therapeutically beneficial. As noted above, there is evidence linking it to CNS functions including those modulating anxiety, depression and reward systems. Due to its multifunctional roles, the effects of OXY in modulating nociceptive transmission and pain perception can be explained through both physiological and psychological mechanisms. It has been suggested that oxytocinergic activity may be closely linked with the endogenous opioid system. Support for this notion comes from animal studies which have revealed that OXY administration into CNS sites such as the periaqueductal grey results in anti-nociception that can be blocked by the administration of a mu or kappa opioid antagonist [49-55]. It has been proposed that OXY is an active mechanism underlying acupuncture-induced analgesia [56-57]. One plausible psychological mechanism linking OXY with pain is that OXY decreases pain sensitivity by improving mood. Indeed, animal and human studies have shown that the administration of OXY affects mood states by reducing anxiety and depressive symptoms as well as mitigating stress responses [58-61]. Whether OXY exerts its pain attenuating effects directly or indirectly by 
improving mood and reducing anxiety remains a topic in need of additional research.

Regardless, the end result appears to be the same; OXY reduces pain sensitivity $[62,63]$.

\section{Organization of Review}

The primary purpose of this article is to provide a focused and critical review of the recent advances made to date in the endeavor to better understand the analgesic properties of OXY as well as its role in the experience of nociception and pain perception. OXY may directly impact pain through centrally-mediated effects on areas of the central nervous system important to the experience of pain including the limbic system, brainstem, and spinal cord [64]. In addition to any direct pain attenuating effects, it has been suggested that OXY could indirectly influence pain via its documented anti-depressive and anxiolytic properties [65]. In the first part of this review we briefly discuss the pharmacology of OXY including its neurohormonal effects and pharmacokinetics. This will be followed by a presentation of literature from human and non-human animal studies, respectively, highlighting the role of $\mathrm{OXY}$ in analgesia and pain. Finally, we conclude by discussing some potential physiological and psychological mechanisms underlying the analgesic properties of OXY.

\section{Pharmacology}

OXY is an endogenous polypeptide that is produced in magnocellular neurons of the SON and PVN of the hypothalamus with sites of release in the posterior pituitary. OXY is highly homologous to arginine vasopressin, the other neurohormone released by the posterior pituitary, differing by only 2 amino acids [66,67]. OXY, which is only nine peptides long, is synthesized from a prohormone by enzymatic cleavage. The cleavage results in two peptides, OXY and neurophysin. Neurophysin does not seem to have signaling properties but appears to be important in OXY packaging and processing in secretory granules $[68,69]$. While the majority of OXY is transported to, and released from, the posterior pituitary into the blood, significant amounts are transported along axons or dendrites and released in different parts of the CNS including the spinal dorsal horn. Specifically, oxytocinergic neurons from the PVN send axonal projections to the superficial and central laminae of the spinal cord [69-72], which closely corresponds with OXY receptor expression as determined by autoradiographic binding [73,74]. Supraspinal sites appear to be the only sources of OXY in the spinal cord because neither dorsal horn neurons nor primary afferent neurons express significant levels of OXY [75]. Intravenous OXY has a short half-life of 15 minutes, is metabolized by hepatic and plasma oxytocinases, and the degradation products are excreted in the urine. Synthetic oxytocin is used clinically for induction of labor, control of post-partum hemorrhage, and facilitation of lactation. Several oxytocin receptor antagonist peptides are currently available, but none of them are approved for clinical usage. Non-peptide OXY agonists are currently under development [76].

Only one selective receptor for OXY, known as OXTR, has been characterized although oxytocin can act via vasopressin receptors at high concentrations [66,67]. OXTR is a rhodopsin type G-protein coupled receptor with seven transmembrane regions [76]. Upon ligand binding, the receptor activates $\mathrm{Gq} / 11$ and $\mathrm{G}$ which together activate phospholipase $\mathrm{C}$ (PLC). PLC then generates diacylglycerol (DAG) and 1,4,5-inositol triphosphate (IP3). 
DAG activates protein kinase $\mathrm{C}(\mathrm{PKC})$ which modulates protein activity by phosphorylation [77]. IP3 facilitates the release of intracellular $\mathrm{Ca} 2+[68,78]$ and results in alteration of other cellular structures such as purinergic receptor channels [79]. OXTR localization has been performed using immunohistochemistry, in situ hybridization, and a gene deletion mouse model. Localization in the CNS appears to be relatively widespread. Interestingly, localization in the spinal cord is limited to the superficial dorsal horn $[68,74,76]$. As a general rule, both OXY and OXTR expression is higher in females at all CNS sites and can be strongly influenced by steroid hormones [76]. Oxytocinergic neurons in the PVN are activated by noxious deep tissue (visceral) stimuli as determined by c-fos expression $[80,81]$.

\section{Analgesic Effects of Oxytocin in Humans}

A limited evidence base in humans suggests that OXY has the potential to modulate somatosensory transmission, particularly pain perception. This evidence has been derived from correlational studies that examined plasma concentrations of OXY in relation to pain, as well as randomized and placebo controlled studies that assessed the analgesic effects of exogenously administered OXY. Despite various differences in study methodology and sample heterogeneity, research in humans generally suggests that low levels of endogenous OXY may be a component of many chronic pain conditions as well as related to increased pain sensitivity. Further, the exogenous administration of OXY seems to decrease pain sensitivity. At the time this review was written, to the best of our knowledge there were five existing studies that examined endogenous OXY concentrations in blood plasma [82-86], seven studies that administered exogenous OXY an compared it to placebo [80, 86-91] and a single case study of OXY administered exogenously for the management of intractable cancer pain [92].

Endogenous OXY concentrations were found to either be significantly lower among patients with a chronic pain condition compared with healthy controls, or associated with enhanced pain sensitivity in all five of the studies that assessed plasma OXY concentrations. For instance, two separate studies found that plasma OXY concentrations were significantly lower among children experiencing recurrent abdominal pain when compared to pain-free children matched for age and sex [82,83]. In a study conducted by Yang [86], it was revealed that adults with acute and chronic low back pain possessed significantly lower blood plasma concentrations of OXY compared to healthy controls. One study indicated that there was no significant difference in blood plasma concentrations of OXY between women with fibromyalgia and healthy controls; however, low concentrations of blood plasma OXY were significantly associated with ratings of greater pain, stress, and depression among the fibromyalgia patients [84]. Finally, in a sample of healthy women subjected to multiple psychophysical pain testing modalities, it was revealed that low levels of plasma OXY were associated with reduced pain tolerance for noxious cold and ischemic stimuli [85].

The seven studies and the single case study that evaluated the effects of exogenously administered OXY on pain in humans have produced somewhat mixed results. Despite this inconsistency, the majority of these studies have found that exogenous OXY administration is reliably associated with decreases in pain sensitivity. For example, one study found that 
intrathecal OXY administration resulted in a dose-dependent reduction of pain in a placebocontrolled evaluation of men and women with acute or chronic low back pain [86]. Another placebo-controlled study found that continuous intravenous infusion of OXY at doses equal to or greater than $20 \mathrm{mU} / \mathrm{min}$ significantly increased thresholds for colonic distention pain among adults with irritable bowel syndrome [87]. In an early study that incorporated the inhalation of low doses of OXY (i.e., intranasal administration), a group of pain-free individuals who randomly received inhaled OXY reported significantly less finger prick pain compared to the group that inhaled a placebo agent [90]. Likewise, a more recent study found that the intranasal administration of OXY was significantly related, in a dosedependent manner, to reports of decreased headache frequency and pain severity in a sample of individuals with chronic migraine [80]. Administration of OXY has also been shown to decrease pain in healthy adults, such that OXY applied intranasally resulted in increased pain thresholds for a noxious cold water stimulus when compared to placebo [91]. It has also been reported that intraventricular OXY administration appreciably lessened intractable thoracic cancer pain in a single case study involving a terminally ill patient with mesothelioma [92]. Despite these promising results, two studies reported non-significant associations between exogenous OXY administration and pain. In a study of women with refractory constipation conducted by Ohlsson and colleagues, intranasal administration of OXY did not demonstrate a significant advantage over placebo for constipation relief. However, further analyses revealed that OXY administration resulted in a significant reduction in reported abdominal discomfort and a non-significant reduction in reported abdominal pain [88]. Lastly, in a small sample of healthy, pain-free men, it was found that intranasal administration of OXY was unrelated to ratings of pain unpleasantness in response to noxious electrical stimulation [89].

A noteworthy limitation of the few human studies that have examined OXY in relation to pain is that the peripheral versus central effects of OXY cannot be directly compared. This is due to the different means by which OXY was either assessed or administered in these studies. For those studies that found significant differences in peripheral levels of endogenous OXY in blood plasma between individuals with a pain condition compared to healthy controls, it remains to be determined whether there are also significant differences in central (i.e., within the CNS) levels of OXY. Although peripheral and central release of OXY appears to be coordinated [93], plasma concentrations of OXY do not always reflect central concentrations [94,95]. How differences between peripheral and central OXY concentrations might be related to pain experiences as well as chronic pain conditions remains an area in need of future research. Similarly, the studies that have exogenously administered OXY have done so using methods that delivered the OXY either peripherally (e.g., intravenous infusion) or centrally (e.g., intrathecal injection). Some routes of administration, such as intranasal inhalation, have both central (through cribiform plate to base of brain) and peripheral (through vascular absorption) routes of delivery. Any potential differences in the experience of pain in humans that might be related to exogenously stimulating peripheral versus central OXY receptors have yet to be addressed. Additional studies are needed to determine whether differences in peripheral versus central OXY concentrations, as well as peripheral versus central administration routes, differentially affect the pain experiences of humans. It is worth noting that intranasal administration has 
been found to be particularly useful in experimental studies due to the relatively noninvasive nature of the drug delivery method [96,97]. Sufficient numbers of studies have been performed the incorporated intranasal oxytocin, and accordingly, recommendations for the standardization of this delivery method have been proposed [98].

\section{Effects of oxytocin on mood factors in humans}

Research supports several candidate psychological mechanisms mediating the pain relieving effects of OXY, including enhancement of subjective well-being, as well as reduction of anxiety and depressive mood states. An increasing number of investigations into the effects of OXY on mood began following an animal study demonstrating that when rats were treated with OXY, they showed a decrease in plasma corticosterone levels as well as a decrease in anxiety behavior in response to stress when compared to treatment with placebo [61]. Along this line, in a placebo-controlled, double-blind study of healthy men, OXY administration resulted in increased subjective reporting of calmness, reduced anxiety, and increased feelings of wellness there were corroborated by a concomitant suppression of salivary free cortisol [24]. Additional studies addressing mood factors have reported that patients with major depression possess significantly reduced levels of plasma OXY [99]; and in turn, low levels of plasma OXY have been associated with greater severity of reported depressive symptoms [100]. OXY has been shown to act as a potent antidepressant [101], which may be related to functional interactions between the serotonergic and oxytocinergic systems. Support for this possibility comes from animal studies which have demonstrated that administration of SSRIs produce short-term increases in plasma OXY levels [102], while OXY infusion has resulted in serotonin release within the median raphe nucleus [103], a primary site of action for SSRIs. A final line of evidence relating OXY to mood factors known to be important for the experience of pain comes from research on alternative therapies such as hypnosis and meditation, which are readily applied to the treatment of chronic pain, and that have been shown to produce feelings of psychological well-being that are mediated by OXY [104]. Taken together, the findings relating OXY to improved mood and sense of well-being have important implications for pain in humans because decreased anxiety and feelings of psychological well-being have been shown to predict better chronic pain outcomes [105-107]. Thus, OXY may exert a positive influence on mood and feelings of well-being that, in turn, predicts decreased pain sensitivity and increased ability for adjustment to chronic pain.

\section{Oxytocin Inhibits Somatic Nociception}

Analgesic effects of OXY have been demonstrated in multiple non-human species including rodents, dogs [108,109], cats [110], and rabbits [111]. OXY administered systemically or at CNS sites such as the spinal intrathecal space [112], PAG [53,54], caudate nucleus [113], nucleus accumbens [114] and amygdala [115] produces analgesia in rodents. Specifically, studies examining the effects of OXY administration have shown rats to be less sensitive to electrical, thermal, chemical and mechanical pain stimuli [49, 116-125], and to also have less pain following acute stress [75], acute inflammation [50,112,126-129], tooth pulp stimulation $[108,109,130]$ and neuropathic injury $[131,132]$. In most cases, this analgesia was reversed with OXTR antagonists. Kang and Park [133] demonstrated poor blood brain 
barrier permeability of OXY but did observe analgesic effects of systemically administered OXY in the tail flick assay. The mechanism by which OXY produces these effects is much less clearly defined. There is mixed evidence that suggests some of the OXY effects may be through a vasopressin receptor mechanism [134] but this has been disputed by others [135137]. OXTR knockout mice had heat and mechanical pain tolerances that were similar to wild-type mice, but the OXTR knockout mice did demonstrate reduced pain tolerance following swim and restraint stressors [121]. Opioidergic, cannabinoid-related, and galaninrelated systems have been implicated in central OXY-related analgesia [49-

$51,54,120,128,130,138]$. However, several studies have failed to observe any effect of naloxone treatment on OXY-related analgesia, and so also proposed non-opioidergic effects [e.g. 139]. Petersson et al [140] demonstrated long-lasting analgesic effects of OXY in ovariectomized rats when given the drug intra-vaginally. Anti-inflammatory effects on both pain-related responses and paw edema were identified after OXY treatment in rats that received footpad injections of carrageenan [136]. An interesting phenomenon noted by Agren et al [141] was that subcutaneous OXY injection produced increased hindpaw withdrawal latencies to nociceptive heat in rats that received the injection as well as their cage-mates that did not receive an injection.

Multiple brainstem nuclei have the ability to actively modulate the processing of sensory information at the level of the spinal cord. Recently, several reports have demonstrated that the PVN of the hypothalamus can also exert anti-nociceptive descending control over dorsal horn spinal neurons [e.g., 142,143], with lesser support of a role for the supraoptic nucleus $[56,137]$. OXY is the main neurotransmitter that is produced in the PVN and oxytocinergic neurons have the appropriate spinal cord connectivity to participate in the modulation of sensory input [144]. However, the mechanism by which OXY exerts its antinociceptive effect remains to be fully elucidated.

It has been suggested that OXY indirectly reduces the activity of spinal dorsal horn neurons following the application of glutamate [145]. Previous work has demonstrated that oxytocinergic fibers from the PVN form axo-dendritic synapses in the superficial laminae of the dorsal horn; however, neither neurons in the dorsal horn nor primary afferent neurons express OXY [71,75,134,146], yet both groups express OXTR [147]. Stimulation of the $\mathrm{PVN}$ results in neuronal activation of the superficial dorsal horn [148].

Two different investigations have used whole-cell patch clamp analysis of spinal cord slices to evaluate the individual superficial lamina neuronal responses to OXY $[75,148]$. Robinson et al. [75] found that OXY inhibited evoked glutamatergic excitatory post synaptic potentials. It has been shown that OXY has no effect in OXY knock-out mice due to a concurrent down-regulation of the OXTR. In addition, Breton et al. [148] found that all lamina II neurons had both spontaneous inhibitory post synaptic currents (sIPSC) and spontaneous excitatory post synaptic currents (sEPSC). The most pronounced effect of OXY was an increase in both the frequency and amplitude of sIPSCs. This effect was blocked by both tetrodotoxin (TTX) and OXTR antagonists, indicating that this effect is both presynaptic to dorsal horn neurons and that it is receptor specific. Interestingly, in the presence of TTX, OXY increases the frequency of glutamatergic mEPSCs in approximately $50 \%$ of superficial lamina neurons. This result is identical to those from whole cell 
recordings in superficial lamina cultures [148]. Together, these results appear to indicate that OXY exerts a widespread presynaptic inhibitory role on dorsal horn neurons, but that it may also increase glutamatergic activation in a smaller population of neurons. Breton et al.

$[148,149]$ hypothesized that this glutamatergic excitatory activity, in a subset of dorsal horn neurons, may represent an amplification system that leads to the facilitation of the more widely characterized inhibitory neurons in the superficial lamina. DeLaTorre et al [150] demonstrated that PVN oxytocinergic activity prevented or interrupted long-term potentiation in spinal dorsal horn neurons.

Several elegant studies have used extracellular single unit recording in the dorsal horn to evaluate the role of OXY on specific cutaneous inputs. In identified spinothalamic tract neurons, PVN stimulation decreases activity of wide dynamic range (WDR) neurons to noxious but not innocuous stimuli [151,152]. A separate population of dorsal horn neurons without receptor fields, known as PVN-ON neurons, are normally silent but are activated upon stimulation of the PVN [153]. Dual recording experiments show an inverse relationship between activity in PVN-ON neurons and spinothalamic tract neurons [153]. Intrathecal OXTR antagonists and bicuculline, a GABA-A receptor antagonist, eliminate the WDR neuronal responses to PVN stimulation [154]. These results indicate that the dorsal horn neuronal response to PVN stimulation is due to OXY and that activation of GABAergic systems is necessary in the process. The authors of these studies hypothesize that descending PVN neurons synapse on GABAergic interneurons in the dorsal horn. These GABAergic interneurons are then thought to form inhibitory synapses on the afferent terminals of A-delta and C-fibers, but not A-beta fibers [152].

\section{Oxytocin Inhibits Visceral Nociception}

In contrast to the role of OXY in somatic nociceptive modulation, minimal work has been performed evaluating the role of OXY on dorsal horn neuronal responses to noxious visceral stimulation. The first published evidence of the anti-nociceptive effect of OXY on noxious visceral stimulation was initially undertaken following anecdotal reports that women with a painful bladder syndrome known as interstitial cystitis experience decreased pain while breastfeeding [155]. Consistent with this human observation, lactating rats had decreased visceromotor response to urinary bladder distention [155]. In addition, rats that received intraperitoneal OXY also had decreased visceromotor response to urinary bladder distention and this response was reversed by an OXTR antagonist. Following up on this observation, Engle et al [156] demonstrated inhibitory effects of oxytocin administered intrathecally on both visceromotor reflex responses to urinary bladder distension as well as dorsal horn neurons that were excited by the same stimulus. Again, these effects of OXY could be reversed pharmacologically by OXTR antagonists. Notable was the observation that other dorsal horn neurons became activated by the OXY administration in a fashion similar to the PVN-ON neurons noted above [153]. Together these data provide strong evidence that spinally delivered OXY provides anti-nociception to noxious visceral stimulation. 


\section{Conclusions}

Deep tissue chronic pain conditions are of immense clinical importance because: 1) These conditions are generally associated with anxiety and depression, and 2) standard drug treatments for these conditions often do not provide effective analgesia and are associated with significant side-effect profiles as well as abuse potential. OXY and other agents acting through the OXTR would appear to be ideal candidates for the treatment of deep tissue chronic pain conditions. Studies in humans have demonstrated pain-relieving effects of OXY, particularly in experimental measures of deep tissue sensation (ischemic pain/muscle pain) or in deep tissue pain disorders (irritable bowel syndrome, migraine). Non-human animal studies are congruent with these human studies and have expanded on both the physiology and pharmacology of OXY and OXTR. Exogenously administered OXY has been demonstrated to produce minimal toxicity at appropriate doses [157] and more importantly, is multifunctional in its actions. Beneficial effects of OXY have been noted in studies of anxiety, depression, sexual dysfunction and drug addiction. Taken together, OXY appears to have potential benefit for also treating the co-morbidities that accompany deep tissue pains, and may even treat some of the problems produced by more traditional treatments for pain such as opioids. Preliminary evidence suggests that OXY is a novel analgesic worthy of additional study to help better determine its value as a therapeutic agent. What is currently lacking at this time is OXY research addressing long-term analgesic efficacy, long-term safety and toxicity, as well as important assessments related to mechanisms of action. These and other studies exploring novel application of OXY and OXTR agonists simply await support, creativity and effort so that our understanding of these agents may be enhanced.

\section{Acknowledgements}

This review was supported by DOD grant W81XWH-11-1-0452 (M.T.R.), NIH DK51413 (T.J.N.), and a Future Leaders in Pain Research Award from the American Pain Society (B.R.G.)

\section{List of abbreviations}

$\begin{array}{ll}\text { CNS } & \text { central nervous system } \\ \text { DAG } & \text { diacyl glycerol } \\ \text { EPSP } & \text { excitatory post-synaptic potential } \\ \text { IBS } & \text { irritable bowel syndrome } \\ \text { IC/BPS } & \text { interstitial cystitis/bladder pain syndrome } \\ \text { IP3 } & \text { inositol triphosphate } \\ \text { IPSP } & \text { inhibitory post-synaptic potential } \\ \text { OXY } & \text { oxytocin } \\ \text { OXTR } & \text { oxytocin receptor } \\ \text { PLC } & \text { phospholipase C }\end{array}$




$\begin{array}{ll}\text { PKC } & \text { protein kinase C } \\ \text { PVN } & \text { periventricular nucleus } \\ \text { SNRI } & \text { serotonin-norepinephrine reuptake inhibitors } \\ \text { SSRI } & \text { serotonin specific reuptake inhibitors } \\ \text { SON } & \text { supraoptic nucleus }\end{array}$

\section{References}

1. Committee on Advancing Pain Research, Care, and Institute of Medicine. Relieving pain in America: A blueprint for transforming prevention, care, education, and research. National Academies Press; 2011.

2. Manchikanti L, Singh V, Datta S, Cohen SP, Hirsch JA. Comprehensive review of epidemiology, scope and impact of spinal pain. Pain Physician. 2009; 12:E35-E70. [PubMed: 19668291]

3. Turk DC. Clinical effectiveness and cost-effectiveness of treatments for patients with chronic pain. Clin J Pain. 2002; 18:355-365. [PubMed: 12441829]

4. Verhaak PF, Kerssens JJ, Dekker J, Sorbi MJ, Bensing JM. Prevalence of chronic benign pain disorder among adults: a review of the literature. Pain. 1998; 77:231-239. [PubMed: 9808348]

5. Gaskin DL, Richard P. The economic costs of pain in the United States. J Pain. 2012; 13:715-724. [PubMed: 22607834]

6. Chou R, Fanciullo GJ, Fine PG, et al. American Pain Society-American Academy of Pain Medicine Opioids Guidelines Panel. Clinical guidelines for the use of chronic opioid therapy in chronic noncancer pain. J Pain. 2009; 10:113-130. [PubMed: 19187889]

7. Benyamin R, Trescot AM, Datta S, Buenaventura R, Adlaka R, Sehgal N, Glaser SE, Vallejo R. Opioid complications and side effects. Pain physician. 2008; 11(2 Suppl):S105-S120. [PubMed: 18443635]

8. Furlan AD, Sandoval JA, Mailis-Gagnon A, Tunks E. Opioids for chronic noncancer pain: a metaanalysis of effectiveness and side effects. Canadian Medical Association Journal. 2006; 174(11): 1589-1594. [PubMed: 16717269]

9. Ansari A. The efficacy of newer antidepressants in the treatment of chronic pain: a review of current literature. Harv Rev Psychiatry. 2000; 7:257-277. [PubMed: 10689591]

10. Lynch ME. Antidepressants as analgesics: a review of randomized controlled trials. J Psychiatry Neurosci. 2001; 26:30-36. [PubMed: 11212591]

11. Verdu B, Decosterd I, Buclin T, Stiefel F, Berney A. Antidepressants for the treatment of chronic pain. Drugs. 2008; 68:2611-2632. [PubMed: 19093703]

12. Wiffen PJ, Collins S, McQuay HJ, Carroll D, Jadad A, Moore RA. Anticonvulsant drugs for acute and chronic pain. Cochrane Database of Systematic Reviews. 2010; (Issue 1) Art. No.: CD001133.

13. Christoph T, Grünweller A, Mika J, et al. Silencing of vanilloid receptor TRPV1 by RNAi reduces neuropathic and visceral pain in vivo. Biochem Biophys Res Commun. 2006; 350:238-243. [PubMed: 16996476]

14. Neugebauer V. Metabotropic glutamate receptors-important modulators of nociception and pain behavior. Pain. 2002; 98:1-8. [PubMed: 12098611]

15. Richardson JD. Cannabinoids modulate pain by multiple mechanisms of action. J Pain. 2000; 1:214. [PubMed: 14622836]

16. Vanegas H, Schaible H-G. Effects of antagonists to high-threshold calcium channels upon spinal mechanisms of pain, hyperalgeisa, and allodynia. Pain. 2000; 85:9-18. [PubMed: 10692598]

17. Wood JN, Boorman JP, Okuse K, Baker MD. Voltage-gated sodium channels and pain pathways. Dev Biol. 2004; 61:55-71.

18. Juif J-E, Poisbeau P. Neurohumoral effects of oxytocin and vasopressin receptor agonists on spinal pain processing in male rats. Pain. 2013; 154:1449-1456. [PubMed: 23707282] 
19. Murphy D, Konopacka A, Hindmarch C. The hypothalamic-neurophypohyseal system: from genome to physiology. J Neuroendocrinol. 2012; 24:539-553. [PubMed: 22448850]

20. Rash JA, Aguirre-Camacho A, Campbell TS. Oxytocin and pain: a systematic review and syntesis of findings. Clin J Pain. 2013 In press.

21. Stoop R. Neuromodulation by oxytocin and vasopressin. Neuron. 2012; 76:142-159. [PubMed: 23040812]

22. Viero C, Shibuya I, Kitamura N, et al. Oxytocin: crossing the bridge between basic science and pharmacotherapy. CNS Neurosci Ther. 2010; 16:e138-e156. [PubMed: 20626426]

23. Bosch OJ, Meddle SL, Beiderbeck DI, Douglas AJ, Neumann ID. Brain oxytocin correlates with maternal aggression: link to anxiety. J Neurosci. 2005; 25:6807-6815. [PubMed: 16033890]

24. Heinrichs M, Baumgartner T, Kirschbaum C, Ehlert U. Social support and oxytocin interact to suppress cortisol and subjective responses to psychosocial stress. Biol Psychiatry. 2003; 54:13891398. [PubMed: 14675803]

25. Heinrichs M, Meinlschmidt G, Neumann I, et al. Effects of suckling on hypothalamic-pituitaryadrenal axis responses to psychosocial stress in postpartum lactating women. J Clin Endocrinol Metabolism. 2001; 86:4798-4804.

26. Insel TR. The challenge of translation in social neuroscience: a review of oxytocin, vasopressin and affiliative behavior. Neuron. 2010; 65:768-779. [PubMed: 20346754]

27. Kosfeld M, Heinrichs M, Zak PJ, Fischbacher U, Fehr E. Oxytocin increases trust in humans. Nature. 2005; 435:673-676. [PubMed: 15931222]

28. Maejima Y, Iwasaki Y, Yamahara Y, Kodaira M, Sedbazar U, Yada T. Peripheral oxytocin treatment ameliorates obesity by reducing food intake and visceral fat mass. Aging. 2011; 3:11691177. [PubMed: 22184277]

29. Mah BL, van Ijzendoom MH, Smith R, Bakermans-Kranenburg MJ. Oxytocin in postnatally depressed mothers: its influence on mood and expressed emotion. Prog NeuroPsychopharm Biol Psychiatry. 2013; 40:267-272.

30. Mazzuca M, Minlebaev M, Shakirzyanova A, et al. Newborn analgesia mediated by oxytocin during delivery. Front Cell Neurosci. 2011; 5:3. [PubMed: 21519396]

31. Neumann ID, Torner L, Wigger A. Brain oxytocin: differential inhibition of neuroendocrine stress responses and anxiety-related behaviour in virgin, pregnant and lactating rats. Neurosci. 2000; 95:567-575.

32. Panksepp J. Oxytocin effects on emotional processes: separation distress, social bonding, and relationships to psychiatric disorders. Ann N Y Acad Sci. 1992; 652:243-252. [PubMed: 1626832]

33. Zak PJ, Kurzban R, Matzner WT. Oxytocin is associated with human trustworthiness. Horm Behav. 2005; 48:522-527. [PubMed: 16109416]

34. Zak PJ, Stanton AA, Ahmadi S. Oxytocin increases generosity in humans. PLoS ONE. 2007; 2:e1128. [PubMed: 17987115]

35. Anagnostou E, Soorya L, Chaplin W, et al. Intranasal oxytocin versus placebo in the treatment of adults with autism spectrum disorders: a randomized controlled trial. Mol. Autism. 2012; 3:16. [PubMed: 23216716]

36. MacDonald K, Feifel D. Dramatic improvement in sexual function induced by intranasal oxytocin. J Sex Med. 2012; 9:1407-1410. [PubMed: 22458365]

37. Phillips WJ, Ostrovsky O, Galli RL, dickey S. Relief of acute migraine headache with intravenous oxytocin: report of two cases. J Pain Palliat Care Pharmacother. 2006; 20:25-28. [PubMed: 16931475]

38. Modabbernia A, Rezaei F, Salehi B, et al. Intranasal oxytocin as an adjunct to risperidone in patients with schizophrenia: ann 8 week randomized, double-blind, placebo-controlled study. CNS Drugs. 2012 epub Dec 12.

39. McGregor IS, Bowen MT. Breaking the loop: oxytocin as a potential treatment for drug addiction. Horm Behav. 2012; 61:331-339. [PubMed: 22198308]

40. Chapman CD, Frey WH 2nd, Craft S, et al. Intranasal treatment of central nervous system dysfunction in humans. Pharm Res. 2012 epub Nov 8. 
41. MacDonald E, Dadds MR, Brennan JL, Williams K, Levy F, Cauchi AJ. A review of safety, sideeffects and subjective reactions to intranasal oxytocin in human research. Psychoneuroendocrinology. 2011; 36:1114-1126. [PubMed: 21429671]

42. In JH, Choi JW, Jung HS, et al. Severe hypotension and water intoxication developed after an accidental oxytocin overdose in a morbidly obese patient undergoing cesarean section - a case report. Korean J Anesthesiol. 2011; 60:290-293. [PubMed: 21602981]

43. Minowa Y, Hara K, Sata T. A case of myocardial ischemia induced by oxytocin during cesarean section. Masui. 2013; 62:982-984. [PubMed: 23984581]

44. Borg J, Ohlsson B. oxytocin prolongs the gastric emptying time in patients with diabetes mellitus and gastroparesis, but does not affect satiety or volume intake in patients with functional dyspepsia. BMC Research Notes. 2012; 5:148. [PubMed: 22420866]

45. Benoussaidh A, Mauriin Y, Rampin O. Spinal effects of oxytocin on uterinie motility in anesthetized rats. Am J Physiol Regul Integr Comp Physiol. 2004; 287:R446-R453. [PubMed: 15044182]

46. Pandita RK, Nylen A, Andersson K-E. Oxytocini-induced stimulation and inihibition of bladder activity in normal, conscious rats - influence of nitric oxide synthase inhibition. Neurosci. 1998; 85:1113-1119.

47. Amico JA, Challinor SM, Cameron JL. Pattern of oxytocin concentrations in the plasma and cerebrospinal fluid of lactating rhesus monkeys (Macacamulatta): evidence for functionally independent oxytocinergic pathways in primates. J Clin Endocrinol Metab. 1990; 71:1531-1535. [PubMed: 2229310]

48. Cechetto DF, Saper CB. Neurochemical organization of the hypothalamic projection of the spinal cord in the rat. J. Comp Neurol. 1988; 272:579-604. [PubMed: 2901438]

49. Ge Y, Lundeberg T, Yu LC. Blockade effect of mu and kappa opioid antagonists on the antinociception induced by intra-periaqueductal grey injection of oxytocin in rats. Brain Res. 2002; 927:204-207. [PubMed: 11821014]

50. Reeta K, Mediratta PK, Rathi N, Jain H, Chugh C, Sharma KK. Role of kappa- and delta opioid receptors in the antinociceptive effect of oxytocin in formalin-induced pain response in mice. Regul Pept. 2006; 135:85-90. [PubMed: 16712978]

51. Rheeta KH, Mediratta PK, Rathi N, Jin H, Chugh C, Sharma KK. Role of k- and d- opioid receptors in the antinociceptive effect of oxytocin in formalin-induced pain responses in mice. Reg Peptides. 2006; 135:85-90.

52. Bodnar RJ, Nilaver G, Wallace MM, Badillo-Martinez D, Zimmerman EA. Pain threshold changes in rats following central injection of beta-endorphin, met-enkephalin, vasopressin or oxytocin antisera. Int J Neurosci. 1984; 24:149-160. [PubMed: 6094376]

53. Yang J, Li P, Liang JY, Pan YJ, et al. Oxytocin in the periaqueductal grey regulates nociception in the rat. Regul Pept. 2011; 169:39-42. [PubMed: 21545817]

54. Yang J, Liang JY, Li P, et al. Oxytocin in the periaqueductal gray participates in pain modulation in the rat by influencing endogenous opiate peptides. Peptides. 2011; 32:1255-1261. [PubMed: 21439337]

55. Yang J, Yang Y, Chen JM, et al. Central oxytocin enhances antinociception in the rat. Peptides. 2007; 28:1113-1119. [PubMed: 17420069]

56. Yang J, Yang Y, Chen J-M, Liu W-Y, Lin B-C. Effect of hypothalamic supraoptic nucleus on acupuncture analgesia in the rat. Brain Res Bull. 2008; 75:681-686. [PubMed: 18355646]

57. Yang J, Yang Y, Chen JM, Liu WY, Wang CH, Lin BC. Effect of oxytocin on acupuncture analgesia in the rat. Neuropeptides. 2007; 41:285-292. [PubMed: 17664006]

58. Ditzen B, Schaer M, Gabriel B, Bodenmann G, Ehlert U, Heinrichs M. Intranasal oxytocin increases positive communication and reduces cortisol levels during couple conflict. Biol Psychiatry. 2009; 65:728-731. [PubMed: 19027101]

59. Heinrichs M, von Dawans B, Domes G. Oxytocin, vasopressin, and human social behavior. Front Neuroendocrinol. 2009; 30:548-557. [PubMed: 19505497]

60. Parker KJ, Buckmaster CL, Schatzberg AF, Lyons DM. Intranasal oxytocin administration attenuates the ACTH stress response in monkeys. Psychoneuroendocrinology. 2005; 30:924-929. [PubMed: 15946803] 
61. Windle R, Shanks N, Lightman SL, Ingram CD. Central oxytocin administration reduces stressinduced corticosterone release and anxiety behavior in rats. Endocrinology. 1997; 138:2829-2834. [PubMed: 9202224]

62. Bair MJ, Robinson RL, Katon W, Kroenke K. Depression and pain comorbidity: a literature review. Arch Intern Med. 2003; 163:2433-2445. [PubMed: 14609780]

63. Chapman CR, Tuckett RP, Song CH. Pain and stress in a systems perspective: reciprocal neural, endocrine, and immune interactions. J Pain. 2008; 9:122-145. [PubMed: 18088561]

64. Raggenbass M. Vasopressin- and oxytocin-induced activity in the central nervous system: electrophysiological studies using in-vitro systems. Prog Neurobiol. 2001; 64:307-326. [PubMed: 11240311]

65. Ishak WW, Kahloon M, Fakhry H. Oxytocin role in enhancing well-being: a literature review. J Affect Disord. 2011; 130:1-9. [PubMed: 20584551]

66. Manning M, Misicka A, Olma A, et al. Oxytocin and vasopressin agonists and antagonists as research tools and potential therapeutics. J Neuroendocrinol. 2012; 24:609-628. [PubMed: 22375852]

67. Manning M, Stoev S, Chini B, Durroux T, Mouillac B, Guillon G. Peptide and non-peptide agonist and antagonists for the vasopressin and oxytocin V1a, V1b, V2 and OT receptors: research tools and potential therapeutic agents. Prog Brain Res. 2008; 170:473-512. [PubMed: 18655903]

68. Caldwell JD, Mason GA, Stanley DA, Jerdack G, Hruby VJ, Hill P, Prange AJ Jr, Pedersen CA. Effects of nonapeptide antagonists on oxytocin- and arginine-vasopressin-induced analgesia in mice. Regul Pept. 1987; 18:233-241. [PubMed: 3671785]

69. Gimpl G, Fahrenholz F. The oxytocin receptor system: structure, function and regulation. Physiol Rev. 2001; 81:629-683. [PubMed: 11274341]

70. Condes-Lara M, Martinez-Lorenzana G, Rojas-Piloni G, Rodriguez-Jimenez J. Branched oxytocinergic innervations from the paraventricular hypothalamic nuclei to superficial layers in the spinal cord. Brain Res. 2007; 1160:20-29. [PubMed: 17599811]

71. Rousselot P, Papadopoulos G, Merighi A, Poulain DA, Theodosis DT. Oxytocinergic innervation of the rat spinal cord. An electron microscopic study. Brain Res. 1990; 529:178-184. [PubMed: 2282492]

72. Puder BA, Papka RE. Distribution and origin of corticotropin-releasing factor-immunoreactive axons in the female rat lumbosacral spinal cord. J Neurosci Res. 2001; 66:1217-1225. [PubMed: 11746455]

73. Reiter MK, Kremarik P, Freund-Mercier MJ, Stoeckel ME, Desaulles E, Feltz P. Localization of oxytocin binding sites in the thoracic and upper lumbar spinal cord of the adult and postnatal rat: a histoautoradiographic study. Eur J Neurosci. 1994; 6:98-104. [PubMed: 8130936]

74. Jo YH, Stoeckel ME, Freund-Mercier MJ, Schlichter R. Oxytocin modulates glutamatergic synaptic transmission between cultured neonatal spinal cord dorsal horn neurons. J Neurosci. 1998; 18:2377-2386. [PubMed: 9502799]

75. Robinson DA, Wei F, Wang GD, Li P, Kim SJ, Vogt SK, Muglia LJ, Zhuo M. Oxytocinmediates stress-induced analgesia in adult mice. J Physiol. 2002; 540(Pt 2):593-606. [PubMed: 11956346]

76. Lee HJ, Macbeth AH, Pagani JH, Young WS 3rd. Oxytocin: the great facilitator of life. Prog Neurobiol. 2009; 88:127-151. [PubMed: 19482229]

77. Ayar A, Ozcan M, Alcin E, et al. Oxytocin activates calcium signaling in rat sensory neurons through a protein kinase C-dependent mechanism. J Physiol Biochem. 2013 epub, Aug 6, 2013.

78. Hobo S, Hayashida K, Eisenach JC. Oxytocin inhibits the membrane depolarization-induced increase in intracellular calcium in capsaicin sensitive sensory neurons: a peripheral mechanism of analgesic action. Anesth Analg. 2012; 114(2):442-449. [PubMed: 22104073]

79. Yang Q, Wu ZZ, Li ZW, Wei JB, Hu QS. Modulation by oxytocin of ATP-activated currents in rat dorsal root ganglion neurons. Neuropharmology. 2002; 43:910-916.

80. Wang YL, Yuan Y, Yang J, et al. The interaction between the oxytocin and pain modulation in headache patients. Neuropeptides. 2013; 47:93-97. [PubMed: 23375440]

81. Hwang BH, Chang HM, Gu ZH, Suzuki R. C-fos gene expression is increased in the paraventricular hypothalamic nucleus of Sprague-Dawley rats with visceral pain induced by acetic 
acid without detectable changes of corticotrophin-releasing factor mRNA: a quantitative approach with an image analysis systems. Anat Rec (Hoboken). 2007; 290:406-413. [PubMed: 17514764]

82. Alfven G. Plasma oxytocin in children with recurrent abdominal pain. J Pediatr Gastroenterol Nutr. 2004; 38:513-517. [PubMed: 15097440]

83. Alfven G, de la Torre B, Uvnas-Moberg K. Depressed concentrations of oxytocin and cortisol in children with recurrent abdominal pain of non-organic origin. Acta Paediatr. 1994; 83:1076-1080. [PubMed: 7841708]

84. Anderberg UM, Uvnäs-Moberg K. Plasma oxytocin levels in female fibromyalgia syndrome patients. Z Rheumatol. 2000; 59:373-379. [PubMed: 11201002]

85. Grewen KM, Light KC, Mechlin B, Girdler SS. Ethnicity is associated with alterations inoxytocin relationships to pain sensitivity in women. Ethn Health. 2008; 13:219-241. [PubMed: 18568974]

86. Yang J. Intrathecal administration of oxytocin induces analgesia in low back pain involving the endogenous opiate peptide system. Spine (Phila Pa 1976). 1994; 19:867-871. [PubMed: 8009342]

87. Louvel D, Delvaux M, Felez A, et al. Oxytocin increases thresholds of colonic visceral perception in patients with irritable bowel syndrome. Gut. 1996; 39:741-747. [PubMed: 9014776]

88. Ohlsson B, Truedsson M, Bengtsson M, Torstenson R, Sjolund K, Bjornsson ES, Simren M. Effects of long-term treatment with oxytocin in chronic constipation; a double-blind, placebocontrolled pilot trial. Neurogastroenterol Motil. 2005; 17:697-704. [PubMed: 16185308]

89. Singer T, Snozzi R, Bird G, et al. Effects of oxytocin and prosocial behavior on brain responses to direct and vicariously experienced pain. Emotion. 2008; 8:781-791. [PubMed: 19102589]

90. Uryvaev, IuV; Petrov, GA. Decreased pain sensitivity in man after treatment with superlow doses of oxytocin. Biull Eksp Biol Med. 1996; 122:487-489. [PubMed: 8998332]

91. Rash JA, Campbell TS. The effect of intranasal oxytocin administration on acute cold pressor pain: a placebo-controlled, double-blind, within-subjects crossover trial. Psychosom Med. 2014; 76(6): 422-429. [PubMed: 24979580]

92. Madrazo I, Franco-Bourland R, Leon-Meza V, Mena I. Intraventricular somatostatin-14, arginine vasopressin, and oxytocin: analgesic effect in a patient with intractable cancer pain. Appl Neurophysiol. 1987; 50:427-431. [PubMed: 2897190]

93. Wotjak CT, Ganster J, Kohl G, Holsboer F, Landgraf R, Engelmann M. Dissociated central and peripheral release of vasopressin, but not oxytocin, in response to repeated swim stress: new insights into the secretory capacities of peptidergic neurons. Neuroscience. 1998; 85:1209-1222. [PubMed: 9681958]

94. Landgraf R, Neumann ID. Vasopressin and oxytocin release within the brain: a dynamic concept of multiple and variable modes of neuropeptide communication. Front Neuroendocrinol. 2004; 25:150-176. [PubMed: 15589267]

95. Morin V, Del Castillo JR, Authier S, et al. Evidence for non-linear pharmacokinetics of oxytocin in anesthetized rat. J Pharm Sci. 2008; 11:12-24.

96. Bethlehem RAI, van Honk J, Auyeung B, Baron-Cohen S. Oxytocin, brain physiology and functional connectivity: a review of intranasal oxytocin fMRI studies. Psychoneuroendocrinol. 2012 epub Nov 2012.

97. Born J, Lange T, Kern W, McGregor GP, Bickel U, Fehm HL. Sniffing neuropeptides: a transnasal approach to the human brain. Nat Neurosci. 2002; 5:514-516. [PubMed: 11992114]

98. Guastella AJ, Hickie IB, McGuinness MM, et al. recommendations for the standardization of oxytocin nasal administration and guidelines for its reporting in human research. Psychoneuroendocrinology. 2012 epub Dec 20.

99. Frasch A, Zetzsche T, Steiger A, Jirikowski GF. Reduction of plasma oxytocin levels in patients suffering from major depression. Adv Exp Med Biol. 1995; 395:257-258. [PubMed: 8713975]

100. Scantamburlo G, Hansenne M, Fuchs S, et al. Plasma oxytocin levels and anxiety in patients with major depression. Psychoneuroendocrinol. 2007; 32:407-410.

101. Arletti R, Bertolini A. Oxytocin as an antidepressant in two animal models of depression. Life Sci. 1987; 41:1725-1730. [PubMed: 3657379]

102. Uvnäs-Moberg K, Bjökstrand E, Hillegaart V, Ahlenius S. Oxytocin as a possible mediator of SSRI-induced antidepressant effects. Psychopharmacol. 1999; 142:95-101. 
103. Yoshida M, Takayanagi Y, Inoue K, et al. Evidence that oxytocin exerts anxiolytic effects via oxytocin receptor expressed in serotonergic neurons in mice. J Neurosci. 2009; 29:2259-2271. [PubMed: 19228979]

104. Uvnas-Moberg K. Oxytocin may mediate the benefits of positive social interaction and emotions. Psychoneuroendocrinol. 1998; 23:819-835.

105. Asmundson GJG, Katz J. Understanding the co-occurrence of anxiety disorders and chronic pain: state-of-the-art. Depress Anxiety. 2009; 26:888-901. [PubMed: 19691031]

106. Howell RT, Kern ML, Lyubomirsky S. Health benefits: meta-analytically determining the impact of well-being on objective health outcomes. Health Psychol Rev. 2007; 1:83-136.

107. Pressman SD, Cohen S. Does positive affect influence health? Psych Bull. 2005; 131:925-971.

108. Brown DC, Bernier N, Shofer F, Steinberg SA, Perkowski SZ. Effect of intrathecal and intravenous administration of oxytocin on amplitude of the reflex-evoked muscle action potential after electrical stimulation of the tooth pulp in anesthetized dogs. Am J Vet Res. 2002; 63:13541358. [PubMed: 12371759]

109. Brown DC, Perkowski S. Oxytocin content of the cerebrospinal fluid of dogs and its relationship to pain induced by spinal cord compression. Vet Surg. 1998; 27:607-611. [PubMed: 9845225]

110. Blum B, Israeli J. Oxytocin antagonism of hypothalamic-induced angina-like ECG changes and pressor effects in the cat. Experientia. 1983; 39:1349-1351. [PubMed: 6653722]

111. Tallarida G, Baldoni F, Peruzzi G, Brindisi F, Raimondi G, Sangiorgi M. Cardiovascular and respiratory chemoreflexes from the hinidlimb sensory receptors evoked by intra-arterial injection of bradykinin and other chemical agents in the rabbit. J Pharmacol Exp Ther. 1979; 208:319329. [PubMed: 762667]

112. Yu SQ, Lundeberg T, Yu LC. Involvement of oxytocin in spinal antinociception in rats with inflammation. Brain Res. 2003; 983:13-22. [PubMed: 12914962]

113. Yang J, Pan YJ, Zhao Y, et al. Oxytocin in the rat caudate nucleus influences pain modulation. Peptides. 2011; 32:2104-2107. [PubMed: 21903147]

114. Gu XL, Yu LC. Involvement of opioid receptors in oxytocin-induced antinociception in the nucleus accumbens of rats. J Pain. 2007; 8:85-90. [PubMed: 17097925]

115. Han Y, Yu LC. Involvement of oxytocin and its receptor in nociceptive modulation in the central nucleus of amygdala of rats. Neurosci Lett. 2009; 454:101-104. [PubMed: 19429063]

116. Arletti R, Benelli A, Bertolini A. Influence of oxytocin on nociception and morphine antinociception. Neuropeptides. 1993; 24:125-129. [PubMed: 8474630]

117. Uvnas-Moberg K, Alster P, Petersson M, Sohlstrom A, Bjorkstrand E. Postnatal oxytocin injections cause sustained weight gain and increased nociceptive thresholds in male and female rats. Ped Res. 1998; 43:344-348.

118. Uvnas-Moberg K, Bruzelius G, Alster P, Bileviciute I, Lundeberg T. Oxytocin increases and a specific oxytocin antagonist decreases pain threshold in male rats. Acta Physiol Scand. 1992; 144:487-488. [PubMed: 1605050]

119. Uvnas-Moberg K, Bruzelius G, Alster P, Lundeberg T. The antinociceptive effect of nonnoxious sensory stimulation is mediated partly through oxytocinergic mechanisms. Acta Physiol Scand. 1993; 149:199-204. [PubMed: 8266809]

120. Gao L, Yu LC. Involvement of opioid receptors in the oxytocin-induced antinociception in the central nervous system of rats. Regul Pept. 2004; 120:53-58. [PubMed: 15177920]

121. Schorscher-Petcu A, Sotocinal S, Ciura S, et al. Oxytocin-induced analgesia and scratching are mediated by the vasopressin-1A receptor in the mouse. J Neurosci. 2010; 30:8274-8284. [PubMed: 20554879]

122. Xu XJ, Wiesenfeld-Hallin Z. Is systemically administered oxytocin an analgesic in rats? Pain. 1994; 57:193-196. A. [PubMed: 8090516]

123. Xu XJ, Wiesenfeld-Hallin Z. Intrathecal oxytocin facilitates the spinal nociceptive flexor reflex in the rat. Neuroreport. 1994; 5:750-752. B. [PubMed: 8018844]

124. Caldwell, HK.; Young, WS. Oxytocin and Vasopressin: Genetics and Behavioral Implications. In: Lajtha, A.; Lim, R., editors. Handbook of Neurochemistry and Molecular Neurobiology. Springer US; 2006. p. 573-607. 
125. Lund I, Yu L-C, Uvnas-Moberg K, et al. Repeated massage-like stimulation induces long-term effects on nociception: contribution of oxytocinergic mechanisms. Eur J Neurosci. 2002; 16:330338. [PubMed: 12169113]

126. Petersson M, Wiberg U, Lundeberg T, Uvnas-Moberg K. Oxytocin decreases carrageenan induced inflammation in rats. Peptides. 2001; 22:1479-1484. [PubMed: 11514032]

127. Padhy BM, Kumar VL. Inhibition of Calotropic procera latex-iduced inflammatory hyperalgesia oxytocin and melatonin. Mediators of Inflamm. 2005; 6:360-365.

128. Russo R, D-Agostino B, Raso GM, et al. Central administration of oxytocin reduces hyperalgesia in mice: implication for cannabinoid and opioid systems. Peptides. 2012; 38:81-88. [PubMed: 22917880]

129. Chow L-H, Tao P-L, Chen J-Cm, Liao R-M, Chang E-P, Huang EY-K. A possible correlation between oxytocin-induced and angiotensive IV-induced anti-hyperalgesia at the spinal leveling rats. Peptides. 2013; 39:21-28. [PubMed: 23142109]

130. Zubrzycka M, Fichna J, Janecka A. Inhibition of trigemino-hypoglossal reflex in rats byoxytocin is mediated by mu and kappa opioid receptors. Brain Res. 2005; 1035:67-72. [PubMed: 15713278]

131. Condes-Lara M, Maie IA, Dickenson AH. Oxytocin actions on afferent evoked spinal cord neuronal activities in neuropathic but not in normal rats. Brain Res. 2005; 1045:124-133. [PubMed: 15910770]

132. Gutierrez S, Liu B, Hayashida K-I, Houle TT, Eisenach JC. Reversal of peripheral nerve injuryinduced hypersensitivity in the postpartum period: role of spinal oxytocin. Anesthesiol. 2013; 118:152-159.

133. Kang YS, Park JH. Brain uptake and the analgesic effect of oxytocin - its usefulness as an analgesic agent. Arch Pharm Res. 2000; 23:391-395. [PubMed: 10976589]

134. Schorscher-Petcu A, Dupre A, Tribollet E. Distribution of vasopressin and oxytocin binding sites in the brain and upper spinal cord of the common marmoset. Neurosci Letts. 2009; 461:217-222. [PubMed: 19539696]

135. Rojas-Piloni G, Mejia-Rodriguez R, Martinez-Lorenzana G, Condes-Lara M. Oxytocin, but not vassopressin, modulates nociceptive responses in dorsal horn neurons. Neurosci Lett. 2010; 476:32-35. [PubMed: 20371376]

136. Yimiya R, Ben-Eliyahu, Shauvit Y, Marek P, Liebeskind JC. Stimulation of the hypothalamic paraventricular nucleus produces analgesia not mediated by vasopressin or endogenous opioids. Brain Res. 1990; 537:169-174. [PubMed: 1982239]

137. Yang J, Liang JY, Zhang XY, et al. Oxytocin, but not arginine vasopressin is involving in the antinociceptive role of hypothalamic supraoptic nucleus. Peptides. 2011; 32:1042-1046. [PubMed: 21310203]

138. Lundeberg T, Meister B, Bjorkstrand E, Uvnas-Moberg K. Oxytocin modulates the effects of galanin in carrageenan-induced hyperalgesia in rats. Brain Res. 1993; 608:181-185. [PubMed: 7684311]

139. Lundeberg T, Uvnas-Moberg K, Agren G, Bruzelius G. Anti-nociceptive effects of oxytocin in rats and mice. Neurosci Lett. 1994; 170:153-157. [PubMed: 8041495]

140. Petersson M, Eklund M, Uvnas-Moberg K. Oxytocin decreases corticosterone and nociception and increases motor activity in OVX rats. Maturitas. 2005; 51:426-433. [PubMed: 16039417]

141. Agren G, Uvnas-Moberg K, Lundeberg T. Olfactory cues from an oxytocin-injected male rat can induce anti-nociception in its cagemates. Neuroreport. 1997; 8:3073-3076. [PubMed: 9331916]

142. Martinez-Lorenzana G, Espinosa-Lopez L, Carranza M, et al. PVN electrical stimulation prolongs withdrawal latencies and releases oxytocin in cerebrospinal fluid, plasma, and spinal cord tissue in intact and neuropathic rats. Pain. 2008; 140:265-273. [PubMed: 18823708]

143. Miranda-Cardenas Y, Rojas-Piloni G, Martinez-Lorenzana G, et al. Oxytocin and electrical stimulation of the paraventricular hypothalamic nucleus produce antinociceptive effects that are reversed by an oxytocin antagonist. Pain. 2006; 122:182-189. [PubMed: 16527400]

144. Rinaman L. Visceral sensory inputs to the endocrine hypothalamus. Front Neuroendocrinol. 2007; 28:50-60. [PubMed: 17391741] 
145. Condes-Lara M, Gonzalez NM, Martinez-Lorenzana G, Delgado OL, Freund-Mercier MJ. Actions of oxytocin and interactions with glutamate on spontaneous and evoked dorsal spinal cord neuronal activities. Brain Res. 2003; 976:75-81. [PubMed: 12763624]

146. Swanson LW, McKellar S. The distribution of oxytocin- and neurophysin-stained fibers in the spinal cord of the rat and monkey. J Comp Neurol. 1979; 188:87-106. [PubMed: 115910]

147. Moreno-Lopez Y, Martinez-Lorenzana G, Condes-Lara M, Rojas-Piloni G. Identification of oxytocin receptor in the dorsal horn and nociceptive dorsal root ganglion neurons.

Neuropeptides. 2012 epub Oct 24.

148. Breton JD, Veinante P, Uhl-Bronner S, et al. Oxytocin-induced antinociception in the spinal cord is mediated by a subpopulation of glutamatergic neurons in lamina I-II which amplify GABAergic inhibition. Mol Pain. 2008; 4:19. [PubMed: 18510735]

149. Breton JD, Poisbeau P, Darbon P. Antinociceptive action of oxytocin involves inhibition of potassium channel currents in lamina II neurons of the rat spinal cord. Mol Pain. 2009; 5:63. [PubMed: 19909537]

150. DeLaTorre S, Rojas-Piloni G, Martinez-Lorenzana G, Rodriguez-Jimenez J, Villanueva L, Condes-Lara M. Paraventricular oxytocinergic hypothalamic prevention or interruption of longterm potentiation in dorsal horn nociceptive neurons: electrophysiological and behavioral evidence. Pain. 2009; 144:320-328. [PubMed: 19493620]

151. Rojas-Piloni G, Martinez-Lorenzana G, DelaTorre S, Condes-Lara M. Nociceptive spinothalamic tract and postsynaptic dorsal column neurons are modulated by paraventricular hypothalamic activation. Eur J Neurosci. 2008; 28:546-558. [PubMed: 18702726]

152. Condes-Lara M, Rojas-Piloni G, Martinez-Lorenzana G, et al. Paraventricular hypothalamic influences on spinal nociceptive processing. Brain Res. 2006; 1081:126-137. [PubMed: 16497280]

153. Rojas-Piloni G, Lopez-Hidalgo M, Martinez-Lorenzana G, Rodriguez-Jimenez J, Condes-Lara M. GABA-mediated oxytocinergic inhibition in dorsal hornneurons by hypothalamic paraventricular nucleus stimulation. Brain Res. 2007; 1137:69-77. [PubMed: 17229405]

154. Condes-Lara M, Rojas-Piloni G, Martinez-Lorenzana G, Lopez-Hidalgo M, Rodriguez-Jimenez J. Hypothalamospinal oxytocinergic antinociception is mediated by GABAergic and opiate neurons that reduce A-delta and C fiber primary afferent excitation of spinalcord cells. Brain Res. 2009; 1247:38-49. [PubMed: 18996098]

155. Black LV, Ness TJ, Robbins MT. Effects of oxytocin and prolactin on stress-induced bladder hypersensitivity in female rats. J Pain. 2009; 10:1065-1072. [PubMed: 19595642]

156. Engle MP, Ness TJ, Robbins MT. Intrathecal oxytocin inhibits visceromotor reflex and spinal neuronal responses to noxious distention of the rat urinary bladder. Reg Anesth Pain Med. 2012; 37:515-520. [PubMed: 22878524]

157. MacDonald E, Dadds MR, Brennan JL, Williams K, Levy F, Cauchi AJ. A review of safety, sideeffects and subjective reactions to intranasal oxytocin in human research. Psychoneuroendocrinology. 2011; 36(8):1114-1126. [PubMed: 21429671] 